\title{
Tryptophan-tRNA Ligase, Mitochondrial
}

National Cancer Institute

\section{Source}

National Cancer Institute. Tryptophan-tRNA Ligase, Mitochondrial. NCI Thesaurus. Code C132154.

Tryptophan-tRNA ligase, mitochondrial (360 aa, $110 \mathrm{kDa}$ ) is encoded by the human WARS2 gene. This protein is involved in the synthesis of tryptophyl-tRNA. 